\title{
Prediction models for disease events do not always influence clinical practice
}

\author{
Michael Lanuti, MD
}

\author{
From the Division of Thoracic Surgery, Massachusetts General Hospital, Boston, Mass. \\ Disclosures: Author has nothing to disclose with regard to commercial support. \\ Received for publication Dec 10, 2017; accepted for publication Dec 20, 2017; available ahead of print Feb 1, \\ 2018. \\ Address for reprints: Michael Lanuti, MD, 55 Fruit St, Founders 7, Boston, MA 02114 (E-mail: mlanuti@mgh. \\ harvard.edu). \\ J Thorac Cardiovasc Surg 2018;155:1909 \\ $0022-5223 / \$ 36.00$ \\ Copyright (C) 2017 by The American Association for Thoracic Surgery \\ https://doi.org/10.1016/j.jtcvs.2017.12.084
}

$\mathrm{Wu}$ and colleagues ${ }^{1}$ have submitted a well-written and interesting study that attempts to define predictors for lymph node involvement in patients with $\mathrm{T} 1$ esophageal squamous cell carcinoma (ESCC). The authors identified 240 patients who underwent esophagectomy for pT1 ESCC from 2002 to 2010. The incidence of lymph node involvement was $4 \%$ in patients with T1a disease and $21 \%$ in $\mathrm{T} 1 \mathrm{~b}$ disease. No patients received induction therapy and endoscopic ultrasound (EUS) was not routinely used. Multiple techniques of esophagectomy were implemented and all resections were $\mathrm{R} 0$. The prediction model included grade, T1 stage, tumor location, and tumor length with a $\mathrm{C}$-index of 0.78 . The only independent predictive variables on multivariate analysis were tumor location and T1b disease. The authors suggest that endoscopic mucosal resection (EMR) should be used as a diagnostic modality to select which patients may be suitably treated with EMR alone, and which should undergo esophagectomy, based on their estimated risk of having lymph node metastases (LNM).

Developing predictive models that are elegant and simple is challenging and the authors should be congratulated for implementing only 4 parameters to address a very important clinical scenario in early stage esophageal cancer. This model uses a scale of 0 to 100 for each parameter, where total points can reach up to 300 . In my opinion, this scoring system is rather cumbersome and the predictions are built on pathologic data from esophagectomy specimens and not EMR specimens. For the authors to appropriately suggest that diagnostic EMR be used in clinical decision making, all patients in this study would have had both EMR and esophagectomy, so that EMR pathologic data could be used to predict subsequent LNM risk in the resection specimen. In addition, EUS and positron emission tomography were not routinely used in this study cohort, although they are the National Comprehensive Cancer

\section{References} 1902-8.

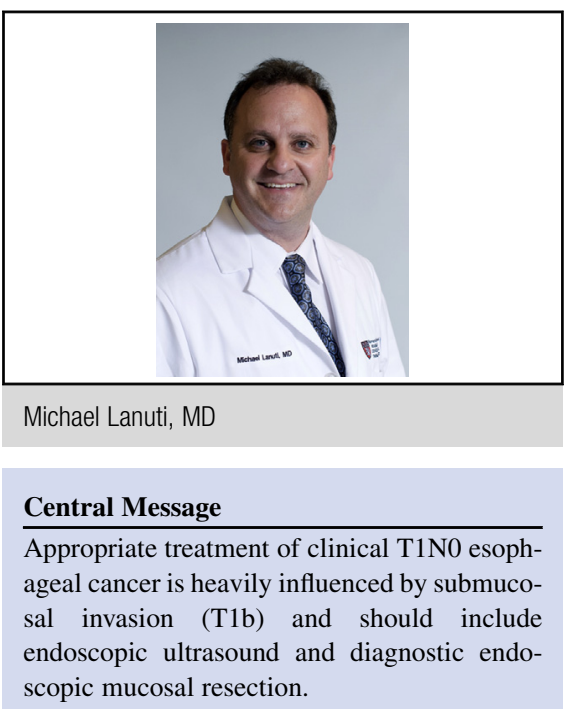

See Article page 1902.

Network's recommendations for the proper workup and staging of patients with esophageal cancer. ${ }^{2}$ It is true that EUS is operator dependent and is not particularly accurate for detecting LNM; however, its use for discriminating T1 disease has been validated in a meta-analysis of 44 studies, including 2880 patients with ESCC. Among patients with T1 disease, EUS had a pooled sensitivity in differentiating T1a and $\mathrm{T} 1 \mathrm{~b}$ of $84 \%$ and $83 \%$, respectively, and a specificity of $91 \%$ and $89 \%$, respectively. ${ }^{3}$ When evaluating patients with clinical early stage (ie, T1N0) esophageal cancer, a recommendation of esophagectomy will be primarily influenced by submucosal invasion (ie, T1b), which can be readily established by EUS and diagnostic EMR despite a prediction model of LNM.

1. Wu J, Chen Q, Shen D, Zhao Q. A prediction model for lymph node metastasis in T1 esophageal squamous cell carcinoma. J Thorac Cardiovasc Surg. 2018;155:

2. Ajani JA, D'Amico TA, Almhanna K, Bentrem DJ, Besh S, Chao J, et al Esophageal and esophagogastric junction cancers, version 1.2015. J Natl Compr Canc Netw. 2015;13:194-227.

3. Luo LN, He LJ, Gao XY, Huang XX, Shan HB, Luo GY, et al. Endoscopic ultrasound for preoperative esophageal squamous cell carcinoma: a meta-analysis. PLoS One. 2016;11:e0158373. 